\title{
NOTAS AL LISIS DE PLATÓN: AMIGOS REALES Y AMIGOS VIRTUALES
}

\author{
NOTES TO PLATO'S LYSIS: \\ REAL FRIENDS AND VIRTUAL ACQUAINTANCES
}

Beatriz Bossi*

\section{IN MEMORIAM}

egún el Sócrates del último diálogo con sus amigos en la S prisión, ser amigo es conocer y cuidar de sí y del otro, y de ser posible, enseñar a morir a lo superfluo e innecesario para concentrarse en lo que vale la pena...

Cuando el año de 2016 Marcelo Marques presentó su ponencia en una sesión plenaria del XI Symposium Platonicum de la IPS, eligió uno de los pasajes más difíciles de interpretar del Fedón: el que se refiere al cálculo de los placeres y dolores. No solamente nos ofreció un trabajo hermenéutico equilibrado y certero, sino que, a mi modo de ver, nos dió a todos una lección práctica.

¿Por qué? Porque él hizo su propio cálculo de los dolores y placeres con sabiduría. Prefirió estar presente entre nosotros para decir su palabra, primero, a favor de su querido país, víctima de la corrupción, y segundo, para ofrecer su interpretación de un pasaje platónico complejo, al precio de aceptar los dolores e incomodidades del viaje después de su operación. Con su propio testimonio, con su serena presencia entre nosotros, a pesar de las dificultades de su condición, y quizás también con la certeza de su muerte próxima, nos dio un ejemplo.

Por eso, cuando Miriam Peixoto me comunicó la idea de hacer un simposio para honrar la memoria de Marcelo, ${ }^{1}$ sentí el entusiasmo de quien desea sumarse a un homenaje para con alguien que no solo ha sido un pensador fecundo, como Carolina Araujo ha mostrado en

\footnotetext{
${ }^{1}$ Gracias Miriam, gracias Fernando por organizar este simposio donde reina la amistad en memoria de Marcelo, como tripulantes de una misma balsa, en un mar turbulento.
}

* Profesora Titular,

Departamento de Historia de la Filosofía, Facultad de Filosofía, Universidad Complutense de Madrid. beabossi@ffilos.ucm.es 
su presentación, sino también, un verdadero seguidor de Sócrates, en la parte más difícil: en su valentía para expresar su palabra en circunstancias adversas y para asumir los nobles peligros que la filosofía plantea.

Ante la vacuidad de este tiempo digital, frente a la objetiva tiranía de los likes, contra la vertiginosa estupidez de los clicks, derramemos generosamente dosis de reflexión filosófica en nuestras cabezas...

Francisco Carpio

\section{INTRODUCCIÓN}

Quizás resulte extraño intentar establecer una comparación entre lo que Platón consideraba como amistad verdadera y las así llamadas 'amistades' a través de las redes sociales. Porque las diferencias saltan a la vista. Y sin embargo, volver a beber en las fuentes antiguas puede ayudarnos a explorar nuestras actitudes con relación al tema de la amistad.

Mi objetivo es desentrañar algunos problemas que plantea la definición de 'amigo' en el enigmático Lisis de Platón desde una lectura exploratoria para, atendiendo a nuestra situación presente, ser capaces de extraer algunas conclusiones para nuestra propia vida.

Dar indicios de lo que es la amistad para Platón no es asunto sencillo de determinar sino bastante escurridizo, ${ }^{2}$ al menos en el primero de los diálogos que parece dedicar al asunto de la philía. Porque el asunto de exploración se desplaza, como ha observado F. Ferrari, ${ }^{3}$ de relaciones simétricas o recíprocas entre individuos, tales como la amistad, en la primera parte del diálogo, a relaciones asimétricas, no necesariamente recíprocas, entre el objeto de deseo y el sujeto que lo padece, como las relaciones eróticas (a partir de 216 c, en la segunda parte).

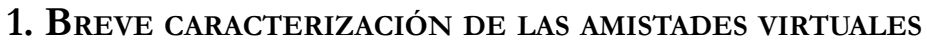

Se supone que Facebook, Instagram y otros portales tienen como objetivo explícito que no existan fronteras y que las personas de todo el mundo puedan comunicarse y establecer relaciones controladas. Sin embargo, en mi limitada experiencia, las así llamadas 'amistades virtuales' tienen ciertas características que podríamos resumir del siguiente modo:

1. Mostración de éxito o de aspectos mayoritariamente positivos, a juicio del emisor, en el plano material o afectivo;

\footnotetext{
${ }^{2}$ Como no tenemos un tratado platónico de la amistad, sino solamente indicios desperdigados en muchos diálogos acerca de lo que es la amistad, y como esos indicios a veces se reflejan en palabras entre los personajes y otras veces se muestran en las actitudes de Sócrates con relación a sus amigos en la acción dramática, el método a seguir debe incluir la atención a los discursos y argumentos, conjuntamente con la observación de gestos y actitudes que denotan los sentimientos y emociones de los personajes.

${ }^{3}$ F. Ferrari, 1998, p. 23.
} 
2. Expectativa de respuesta positiva inmediata que afiance una identificación superficial con el punto de vista del emisor. Abundan expresiones conformistas o de adulación directa;

3. Obsesiva autoreferencia de imágenes y contenidos, con escasa visión de conjunto;

4. Difuminación o desaparición de la línea divisoria entre lo público y lo privado.

Sin duda todos tenemos amigos cercanos que nos conocen con mayor profundidad, nos sostienen en la adversidad y nos ayudan a ser mejores personas. Pero ¿qué pasaría si no cultivásemos casi esas amistades porque nos hemos hecho dependientes de las que nos aprueban sin conocernos? $\mathrm{O}$ ¿qué pasaría si creyésemos que la felicidad coincide con la 'imagen' de la felicidad en términos de éxito material o afectivo? ¿ $\mathrm{O}$ si creyésemos que el número de seguidores determina el valor de una cuenta y de la persona que posee ese dominio? ¿Es que el reino de la cantidad y de la diversión no deja espacio para relaciones interpersonales más humanas? Vayamos al Lisis.

\section{LA ESCENA INCIAL DEL LISIS}

Cuando Sócrates marchaba de la Academia al Liceo, ${ }^{4}$ por el camino externo a la muralla, pasando a través de una portezuela donde se encuentra la fuente de Panops, (con una probable referencia a Hermes 'el que todo lo vigila's) se tropieza con un grupo de jóvenes, entre los cuales distingue a dos amigos: Hipótales y Cetésipo. El primero reconoce a Sócrates y le hace la misma pregunta que Fedro en el diálogo homónimo: ‘ ‘a dónde vas y de dónde vienes?' (203a). Esta pregunta es significativa para nosotros. No sólo porque todo diálogo platónico es un transcurrir desde una cierta ignorancia hacia a un cierto saber (aunque no sea más que un cierto saber de la propia ignorancia), sino porque en este caso particular la trayectoria ficticia de Sócrates parece predecir el destino del propio diálogo, que salió de la Academia de Platón para llegar a manos de Aristóteles, quien se nutrió de él, como se puede comprobar en sus escritos sobre la philía en la Ética a Nicómaco.

La referencia al 'camino exterior a la muralla' (extra muros) nos sitúa: los personajes se encuentran en un sitio de esparcimiento y ejercicio deportivo, fuera del alcance del juicio de

\footnotetext{
${ }^{4}$ La zona de la Academia,al noroeste de Atenas, era un lugar de culto desde la edad de bronce. Platón fundó la Academia en el -387 en el sitio donde el héroe Academo había honrado a los Dióscuros (Cástor y Polux, hermanos de Helena) junto a un olivar sagrado en honor de Atenea, diosa de la sabiduría. Otras manifestaciones religiosas en ese lugar estaban relacionadas con el culto a Prometeo y a Dioniso. En el camino de Atenas a la Academia había sepulcros. El Liceo, en el noreste de la ciudad, era el nombre de un gimnasio en las cercanías de un santuario dedicado a Apolo Licio, en el que además de instalaciones deportivas había un teatro. Aristóteles fundó allí su escuela en el -336. ${ }^{5}$ González, F. (2003, p. 42). Hermes es el dios de los jóvenes atletas que compiten y aman, en el punto del paso de la niñez a la edad adulta; mensajero entre dioses y hombres, intermediario entre límites, puede invitar a la transgresión.
} 
la ciudad, en la intimidad de la palestra, donde los jovencitos modelan sus cuerpos, compiten atléticamente, se persiguen y se esquivan.

Sócrates atraviesa una 'pequeña puerta' fuera del camino trillado. En este diálogo las respuestas de la tradición cultural o de los poetas serán sistemáticamente descartadas hasta dejar a los interlocutores y al propio Sócrates, al menos aparentemente, con las manos vacías. El diálogo abunda en discusiones erísticas, característica de la educación insípida de los jóvenes y particularmente de Menéxenos (211 b) y Cetésipo (211 c c $)^{6}$ cuyo maestro es descrito como un sophistés (204 a 6-7).

Pasemos a la situación de la acción dramática. Hipótales está enamorado de Lisis pero no sabe cómo cortejarlo para ganar su estima; se dedica a adularlo y a cansar a sus amigos, alabando su belleza, su riqueza, el linaje de su familia, sus carros y caballos, etc. Sócrates le indica que de ese modo nunca lo ganará porque la adulación agranda al amado y lo pone cada vez más lejos de su alcance. Para que Hipótales aprenda a tratar a Lisis, Sócrates se ofrece a hacer una demostración de cómo debería hablarle.

Así comienza el diálogo entre Sócrates, que hace el papel del abogado del diablo y el bello Lisis. Sócrates intenta humillar a Lisis diciéndole que, a pesar de ser libre, de hecho es dominado por sus esclavos pedagogos, porque al parecer sus padres, aunque lo estimen, 'ponen trabas a su felicidad, lo tienen esclavizado y no le permiten hacer nada de lo que desea' (209a). Pero Lisis es listo y no cae en la trampa. No se deja amedrentar por las preguntas insidiosas de Sócrates, sino que atribuye las limitaciones que le imponen sus padres a su edad temprana. Sin embargo, Sócrates le hace ver que la causa de tales limitaciones en el uso de artefactos obedece a su grado de conocimientos y destrezas. Aunque su padre no le deja conducir el carro ni los caballos, ni su madre le cede el telar, ambos confían en él cuando quieren que se les lea o se les escriba algo, o cuando quieren que su hijo los deleite con la lira. La conclusión es que 'en aquello en lo que hemos llegado a ser entendidos todos confían en nosotros, griegos y bárbaros, hombres y mujeres' y que cuanto mayor sea el conocimiento, más libres seremos y gobernaremos a otros $(210 \mathrm{~b})$.

En esta primera escena Sócrates ha logrado que los jóvenes comprendan que existe una relación poderosa entre conocimiento y philia. Al parecer, Lisis debe procurar hacerse un 'entendido' para recibir y merecer estima. Ante esta primera conclusión pragmática, se ha objetado que la amistad y las relaciones de parentesco no pueden basarse en la utilidad que se pueda obtener de conocimientos técnicos o especializados de los demás. Sin embargo, salta a la vista que una primera aproximación no significa una conclusión y que el contexto y la finalidad de Sócrates justifican su aproximación al asunto. Comparto la visión de quienes no han querido tomar al pie de la letra el utilitarismo de la concepción de la amistad enseñada al joven Lisis, sino que lo interpretan pedagógicamente como un procedimiento para educar

\footnotetext{
${ }^{6}$ En un aparte, que no carece de complicidad algo cómica, Lisis pide ayuda a Sócrates para que 'lo frene' pero Sócrates, sabiendo lo disputador que es, intenta rehuir el reto 'para no hacer el ridículo', hasta que al final acepta a regañadientes $(211 \mathrm{~b}-\mathrm{c})$.
} 
a Hipótales. ${ }^{7}$ Llegará el momento en que Sócrates hable de un conocimiento del fin último que escapa a la instumentalización, y que coincide con el conocimiento del bien. Sócrates considera que ser amado por ese conocimiento no es vergonzoso sino necesario. (Eutidemo, 282 b 3-6).

Hallamos un indicio revelador de la verdadera philía en la confesión que hace Sócrates al lector acerca de sus intenciones: estuvo a punto de decirle a Hipótales: 'así es preciso dialogar con el amado: rebajándole y haciéndolo de menos, y no como tú, inflándole y deshaciéndote en halagos'. Pero como lo vió angustiado y desorientado, se contuvo y se guardó estas palabras (210e). Aunque Sócrates ha dado una lección a Hipótales, no quiere ponerlo en evidencia. Se contiene, y desiste de hacerse notar, porque se ha dado cuenta de cómo se siente. Observemos en primer lugar que la amistad necesita, como condición de posibilidad, de una cierta complicidad que se reserva al plano privado o intimo. La verdadera amistad no puede crecer ni fortalecerse en la exposición pública permanente. Porque las debilidades y las carencias que el amigo conoce y puede ayudar a solventar o a amenguar sólo pueden tratarse en privado.

En segundo lugar, nos encontramos con la clara indicación de que no se debe adular al amigo. No ayuda ni al emisor (que se humilla) ni al receptor (que se agranda), por la sencilla razón de que la adulación es un juicio falso, y es dañino en la medida en que impide el verdadero progreso hacia el conocimiento. El amigo no puede consentir la vanagloria. ${ }^{8}$ Sócrates se sitúa en las antípodas de la adulación y se revela como el maestro de la parrhèsía, i.e. del decir lo que piensa, sin temor a las consecuencias. ${ }^{9}$

Hipótales desea el favor sexual del amado. No ama a Lisis por sí mismo sino por los bienes asociados a su persona y por el placer erótico que podría prodigarle. Sócrates lo encuentra ridículo porque se elogia a sí mismo como si fuera a ganarlo. Aunque el deseo

\footnotetext{
${ }^{7}$ Véase por ejemplo Narcy (2000, p. 192-193). En su interesante artículo Narcy concluye que la tesis socrática de que la sabiduría es el único bien (tesis central del Eutidemo, compatible con la visión anunciada en el Lisis) es rechazada por ciertos autores como Anscombe o Annas, no por razones de validez lógica, sino sencillamente por diferencias doctrinales.

${ }^{8} \mathrm{El}$ click semiautomatizado de las relaciones virtuales no contribuye, en principio, a progreso alguno. El emoticon 'aplauso' es el símbolo de la aprobación express. Esto no significa que todo aplauso sea adulador ya que también puede ser merecido, pero el click inmediato facilita la repetición de innumerables gestos de aprobación que, de tan frecuentes, pueden resultar vacíos o pueden elevar el umbral de aprobación externo en exceso. Este efecto es peligroso. Porque obliga a focalizar la atención en el sujeto en forma exagerada en lugar de hacerlo en el cumplimiento correcto de la acción que se realiza. Por otra parte, el mecanismo automatizado de las redes no parece facilitar una toma de distancia, un cierto tiempo de pensar críticamente lo que el ojo ve en la imagen o lo que el intelecto elabora a partir de un contenido verbal.

${ }^{9}$ Incontables sentencias reflejan esta actitud de Sócrates, por ejemplo en la Apología frente a los jueces o en el Gorgias frente a Calicles. De modo que parte del cuidado personal incluye aprender a contenerse en la palabra cuando corresponde (como aquí con Hipótales) o no contenerse en absoluto (como con Lisis y tantos otros, sean amigos como Critón, o adversarios como Trasímaco o los jueces).
} 
motiva a Hipótales a hacerse 'amigo' de Lisis, no es suficiente para fundar una relación de $\operatorname{amistad}^{10}$ en sentido pleno.

En general Sócrates humilla a Hipótales, a Lisis, y a Menéxenos a lo largo del diálogo, pero con su estrategia no los pierde como amigos. De algún modo se las ingenia para corregirlos y ponerlos en camino para explorar juntos la verdad. Por otra parte, la supuesta estrategia socrática para rebajar a Lisis contiene un punto de ironía en el caso de Lisis porque éste no da muestras de sentirse humillado por Sócrates, como si adivinase que su interlocutor está probándolo o jugando con él. Cuando el juego termina, Lisis, consciente del ejercicio que ha tenido lugar sobre él, pide en privado a Sócrates que haga lo mismo con Menéxenos. Sócrates le contesta que lo lleve a cabo él mismo ya que ha estado muy atento (211 a). Lo que indica que la puesta a prueba del otro (con la consiguiente humillación o sin ella) es el modo favorito de Sócrates de tratar a los amigos. Queda a los interlocutores la libertad de reaccionar con inteligencia y 'disfrutar' de la prueba o enfadarse con Sócrates en lugar de enfadarse consigo mismos y avanzar (cf. Teeteto, 150e-151b; 210 c 1-5). En cualquier caso, podría decirse que el mayor gesto de amistad socrática consiste en ser elegido por él para ser refutado.

\title{
3. LA ESCENA FINAL: 'NO SABEMOS QUÉ ES UN AMIGO PERO DIRÁN QUE CREEMOS QUE NOS HEMOS HECHO AMIGOS'
}

A fin de explorar las claves interpretativas que Platón deja caer en el diálogo, seguiré el orden inverso a la lectura. Cuando el diálogo acaba, los interlocutores no son capaces de llegar a una definición de la amistad. Y sin embargo, precisamente al final del diálogo, Sócrates, hablando de los esclavos que han venido a buscar a los jovencitos para llevarlos a sus casas, dice:

\begin{abstract}
Ahora, Lisis y Menéxeno, hemos hecho el ridículo, yo que soy viejo y también vosotros. Pues cuando se vayan éstos dirán cómo nosotros creemos que somos amigos unos de los otros - pues yo me cuento entre vosotros - y sin embargo, no hemos sido capaces de llegar a descubrir

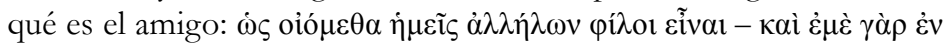

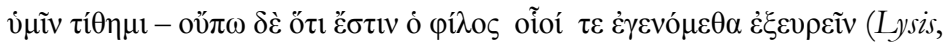
223 b $4-8) .{ }^{11}$
\end{abstract}

\footnotetext{
${ }^{10}$ Bordt (2000, p. 160) ha señalado que es importante 'refutar' a Hipótales para poner en evidencia que la amistad y el amor no pueden reducirse solamente a una emoción intensa. Para construir una relación es necesario apelar a otras fuentes racionales más estables, no basadas exclusivamente, en el apetito y el impulso. Para poder cuidar a alguien es necesario amar algo más alto que uno mismo y que el otro, es preciso vislumbrar otras alturas hacia las que conducirnos.

${ }^{11}$ Bolotin (1977, p. 61, nota 86) en lugar de traducir 'qué es el amigo' traduce: 'si existe un amigo'. El griego lo permite pero el hecho de que Sócrates se cuenta a sí mismo como amigo de los jóvenes, y hable de una cierta rídicula paradoja, no puede autorizar esa traducción.
} 
Si sólo fuera cuestión de cotilleo entre esclavos que no hablan bien el griego y que parece que han bebido demás en la fiesta de Hermes, sus comentarios no deberían importarnos, pero Sócrates sostiene que él se cuenta entre ellos como un amigo, y que han hecho el ridículo porque no han podido definir en qué consiste ser amigo de alguien. El lector adivina que debe volver a leer el diálogo para descubrir cuál es el momento, que le ha pasado desapercibido, en el que estos tres personajes se han hecho amigos.

Al inicio de su diálogo con Menéxenos, Sócrates confiesa que hay algo que desea desde niño, como otros desean caballos, perros, oro u honores; estas cosas a él le importan poco, pero declara que siente una gran pasión por tener amigos

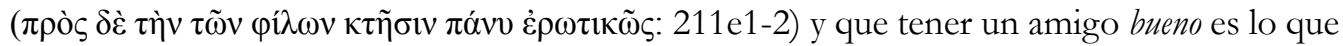

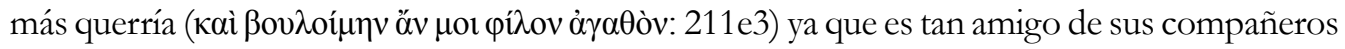

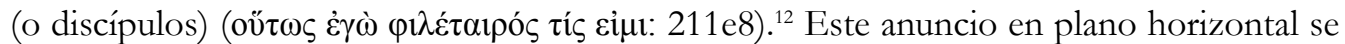
lleva al plano vertical en el punto culminante de la estructura piramidal que organiza este diálogo platónico, y muchos otros. Sócrates no quiere un amigo cualquiera sino un amigo bueno, y más precisamente, según revela la acción dramática, hacerlo mejor, perfeccionarlo, llevarlo hacia su plenitud... o quizás aún mejor, hacerse mejor con él. Ser amigo se revelará como amar el bien con otro para que ambos lleguen a mejorarse mutuamente. O dicho muy brevemente, toda auténtica philía supone compartir un deseo erótico por el bien.

A continuación Sócrates declara:

Viéndoos a vosotros, a tí y a Lisis, me asombro y os felicito porque, siendo tan jóvenes, habéis llegado a poseer tal don de un manera tan rápida y sencilla. Has logrado, rápida y fácilmente que él sea tu amigo y tú el suyo’ (211e8-212a4).

La observación acerca de la rapidez, la sencillez y la facilidad, (propias de muchas relaciones virtuales, como si Sócrates dijera a un joven de hoy que se siente maravillado por la cantidad de amigos y seguidores que se ha hecho en Instagram o en Facebook con tanta facilidad y rapidez) no puede ser sino irónica, porque la acción dramática muestra que estos jóvenes se celan, se persiguen y rivalizan entre ellos de un modo nada sencillo, al punto que cada uno de ellos pide ayuda a Sócrates con relación a otro: Hipótales con relación a Lisis y éste con relación a Menéxenos.

Sócrates agrega que él está tan lejos de haberlo logrado, que no sabe de qué modo se hace uno amigo de otro (212a 4-7). Este comentario también puede parecernos algo irónico, si tenemos en cuenta la fama y el poder de convocatoria que tenía Sócrates en la Atenas de su época. Pero lo importante de esta observación es que el diálogo, más que buscar una definición de amistad, tiene como objetivo investigar el modo en que uno desea, se hace amigo, o ama a alguien o a algo. ${ }^{13}$

\footnotetext{
${ }^{12}$ Según los testimonios de Alcibíades en el Banquete y del propio Sócrates en el Fedón y en el Fedro, Sócrates ama apasionadamente a los jóvenes para conducirlos a la vida filosófica, no para abusar de ellos. ${ }^{13}$ Ferrari (1998, p. 22, 24-25) observa que la respuesta a esta pregunta supone dos factores: la 'precondición' de la amistad, del eros y del apetito es la carencia por parte del sujeto, que es consciente
} 
Comienza aquí una fase indagatoria de corte erístico que no conduce aparentemente a ningún resultado positivo acerca de la amistad. La primera cuestión que se plantea es si en las relaciones eróticas es 'querido' el amante o el amado. No se ponen de acuerdo. Como hay casos en que el amado odia a quien lo ama y ama a quien lo odia, deciden reiniciar la indagación por otro camino. El análisis parece descriptivo.

La segunda vía es apelar a los poetas que dicen que los hombres se vuelven amigos por semejanza. Pero el examen de esta posibilidad los deja con las manos vacías porque caen en una simplificación maniquea que bloquea el proceso de indagación: parten del supuesto de que existen 'los malos', 'los buenos' y 'los neutros'. Los malos no pueden ser amigos de los malos por ser imprevisibles e inestables, por lo que no pueden llegar a hacerse semejantes a sí mismos ni mucho menos podrían ser semejantes a otro y amigo suyo (214d). Tampoco los buenos podrían tener 'interés' en hacerse amigos de los buenos, puesto que siendo buenos, estando ausentes de sus amigos, no los echan de menos porque son autosuficientes, y estando juntos, no sacan 'provecho' en ello (215b).

Es evidente que Sócrates y Menéxenos están explorando esta posibilidad desde una visión utilitarista o interesada de la amistad. ${ }^{14}$ Sócrates quiere mostrar a Menéxenos que el fracaso es inevitable cuando uno no puede liberarse de esta perspectiva. El análisis prosigue. Parecería que los hombres se hacen amigos por la utilidad que pueden obtener de su opuesto: el pobre, del rico; el ignorante, del sabio; el enfermo, del médico (215d). ${ }^{15}$ Sócrates propone que quizás 'lo que no es ni bueno ni malo' sea amigo de lo bueno: $\tau$ ò $\mu \eta ́ \tau \varepsilon$

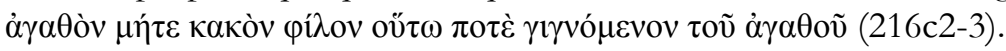

Aturdido por la aporía del discurso, Sócrates busca refugio en un viejo

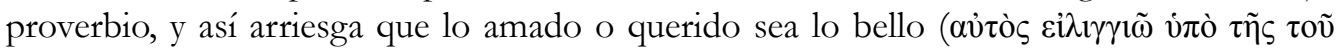

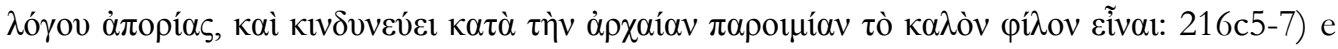

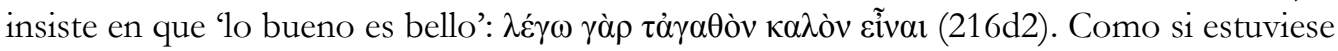
adivinando ( $\dot{\alpha} \pi \mathrm{o} \mu \alpha \tau \varepsilon v o ́ \mu \varepsilon v o \varsigma)$, sostiene que lo que no es ni bueno ni malo es amigo de lo bueno y bello (216d3-4) (lo busca y lo persigue) por la presencia de algo malo (217b). Así también, observa, es el caso del que no es ni sabio ni completamente ignorante, sino que,

de su déficit, y por otra parte, la presencia de un término intencional del proceso concebido como 'causa final', que es identificado con el bien, y resulta ser 'lo propio' del sujeto que desea.

${ }^{14}$ En su estudio sobre el Lisis, Bolotin (1977, p. 139) considera que la amistad, entendida como una relación de amor entre seres humanos, es problemática e ilusoria porque cada amigo ama primariamente su propio bien y al otro, como un medio para su realización. También Vlastos (1981) entiende que, según Platón, la utilidad es una razón suficiente para el amor y la amistad. Por lo que resulta egoista. Adams (1995) y Reshotko (1997), siguiendo a Irwin (1977), también consideran la posición socrática, utilitarista. Para Bordt (2000, p. 161-162) en cambio la utilidad es una condición necesaria de la amistad pero no suficiente.

${ }^{15}$ Aristóteles sigue aparentemente el mismo orden: apelación a los poetas y a los sabios; origen de la amistad por semejanza y desemejanza (Ética Nicomaquea, VIII 1155a32-b8). 
sabiendo que no sabe, busca el saber (218a).$^{16} \mathrm{Y}$ concluye que lo que no es ni bueno ni malo (el cuerpo, el alma y todo lo demás) quiere el bien como fin por la presencia de lo malo (Cf. 218b8-c2; 219a6-b2).

Sin embargo esta no es la última palabra, sino que en este punto Sócrates comienza a desmarcarse de las simplificaciones anteriores de 'los buenos' y 'los malos'. La realidad es compleja, como lo muestra la presencia de lo malo (y de lo bueno) en lo neutro. Este es un paso importante, pero aún hace falta dar un segundo paso para liberarse de la visión popular y utilitaria de la amistad.

Puesto que no siempre buscamos algo en razón de otra cosa en forma interesada, Sócrates considera que las cosas deseadas por causa de otra cosa son como simulacros que

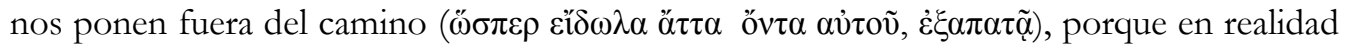
las queremos sólo por causa de otra cosa, mientras que lo primero querido por sí mismo es lo verdaderamente querido $(219 \mathrm{~d} 2-5) \cdot{ }^{17}$

Así resulta que la amistad verdadera no es utilitaria y no busca a otro por los beneficios o utilidades que se derivan de la relación (220b4-5; 6-7). Lo que deseamos como fin en sí mismo y no por otra cosa, eso es el bien. (220b6-7).

Contra la primera conclusión, Sócrates sostiene que aunque el mal desapareciera, aún así desearíamos el bien; después de todo, el mal no es la causa de que las cosas sean queridas, sino, observa, el deseo mismo de lo que uno carece (220e1-2).

La segunda conclusión que supera a la primera establece que: "De lo propio,

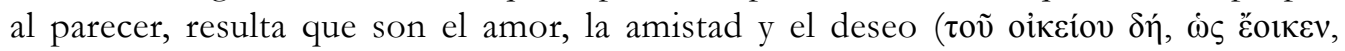

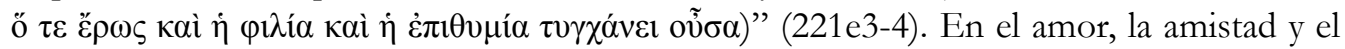
apetito, queremos 'lo propio', lo que nos pertenece por naturaleza, lo que nos corresponde, pero que no poseemos completamente, y por ello lo deseamos.

\section{4. ¿UN DIÁLOGO APORÉTICO?}

Sócrates cree que lo 'propio' no es lo mismo que lo 'semejante' y que, siendo diferentes, ya han encontrado una respuesta a la cuestión de en qué consiste hacerse amigo

\footnotetext{
${ }^{16}$ Bordt (2000) observa que así como la 'sabiduría' de un ser humano consiste sobre todo en desear el saber, análogamente, la 'bondad' de un hombre consiste en desear el bien, y sólo los que desean lo realmente bueno pueden ser amigos (165). A pesar de las apariencias, según este autor, no se ha de creer que para Platón los buenos son realmente autosuficientes; desde el momento en que desean algo, no pueden serlo (166). Que los inestables y desleales no pueden ser amigos ni de sí mismos ni de otros, observa Bordt, es doctrina de Rep. 351c7-352d3 y de Gorgias, 507e1-6. Con relación a la cuestión de la semejanza, señala que Platón no considera la refutación socrática del Lisis como válida, puesto que define la amistad como una relación entre iguales en virtud (Leyes, 837a6 y sgtes.) 166.

17 'Todas las demás cosas de las que decimos que somos amigos por causa de otra, nos engañarían, como si fueran simulacros de ella, mientras que aquello primero querido por sí mismo, sería lo

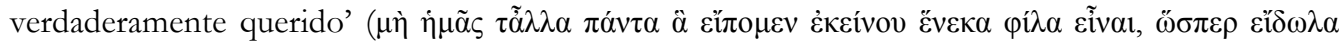

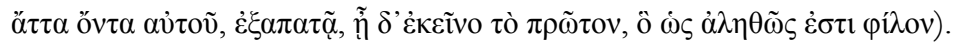


(222b4-5). Pero su convicción no es suficiente; necesita la confirmación de los jóvenes para proseguir: " ¿Queréis pues, dije yo, que como embriagados por el discurso concedamos y

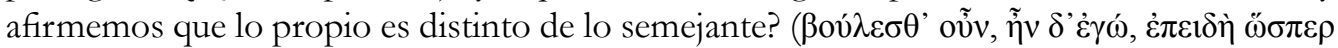

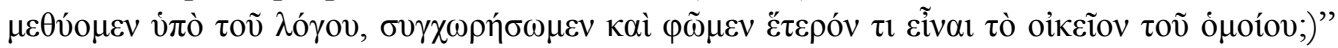
(222c1-3).

Como ellos aceptan la propuesta, Sócrates les pregunta entonces, si aceptan la tesis

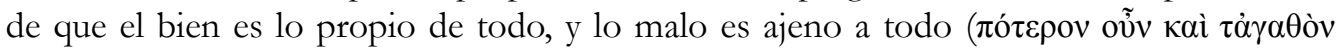

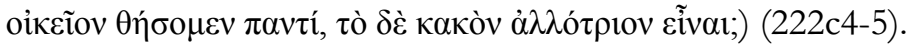

No hay respuesta a esta cuestión por parte de los jóvenes y cuando les pregunta si lo malo es lo propio de lo malo; lo bueno, propio de lo bueno y lo que no es ni bueno ni malo es lo propio de lo que no es ni bueno ni malo, ellos asienten. Pero en este paso lo propio resulta ser lo mismo que lo semejante, tesis que se había acordado rechazar.

Entonces Sócrates les dice:

'Pero ya muchachos hemos vuelto a caer en el argumento que antes habíamos rechazado, a saber: que el injusto y el malo no son menos amigos del injusto y del malo, que el bueno lo es del bueno.' 'Esa parece ser la conclusión’ dijo Menéxenos.

A este personaje casi parece agradarle la aporía. Naturalmente, hay un modo de salir de ella. Si lo propio es diferente de lo semejante, es posible que todo desee el bien, i.e. lo bueno, lo malo y lo neutro. Sin embargo, Sócrates no insiste en esta salida, sino todo lo contrario, parece consentir que Menéxenos y todos ellos se queden con las manos vacías, como si Platón deseara que sea el lector quien encuentre el fallo y descarte la aporía.

Sócrates les pregunta:

- ¿Pero, cómo? Si antes habíamos dicho que lo bueno y lo propio son lo mismo, no será entonces el bueno sólo amigo del bueno?’ Ellos asienten y él dice: 'esto creíamos que ya lo habíamos refutado, no os acordáis? (222d5-8).

Al negar la identidad entre lo propio y lo bueno, caen otra vez en la afirmación de que solamente el bueno puede ser amigo del bueno, cosa que ya habían descartado antes.

Sin embargo, desde mi punto de vista, este pasaje revela que Sócrates no renuncia a que lo propio y el bien son lo mismo para todas las cosas, como había afirmado antes, porque todo es bueno en cierto sentido y lo bueno de cada uno o de cada cosa, es lo que busca el bien en lo otro.

Que Sócrates diga que ‘creían' haberlo refutado no es lo mismo que haberlo refutado. Los buenos no pueden desear ser amigo de otros porque, siendo buenos, son autosuficientes. Esto sería así si los buenos fuesen absolutamente buenos.

Pero todo en este mundo es mixto y relativo a lo deseado por sí mismo como fin último. La discusión con Menéxenos versa sobre los absolutamente buenos y los absolutamente malos, pero si sólo hay lo que es ni absolutamente bueno ni absolutamente 
malo, la antigua refutación no tiene valor ahora. A mi modo de ver, parece que el diálogo acaba en aporía porque no se puede definir lo que es ser amigo, si uno pretende conseguirlo haciendo uso de conceptos absolutos y excluyentes, propios de la erística de Menéxenos, tales como 'bueno absolutamente' o 'malo absolutamente'. Creo que existe una salida y que el diálogo puede ser salvado por el lector, si se siguen las pistas que Platón ha dejado caer en suspenso y se acepta que la realidad es compleja o mixta. En este sentido comparto la posición de F. Ferrari ${ }^{18}$ para quien no estamos ante una aporía objetiva o insalvable en sí misma, que amenace el contenido verdadero y propio del diálogo, sino ante una aporía que corresponde al nivel dialógico-situacional. ${ }^{19}$

En un trabajo anterior ${ }^{20}$ defendí la tesis de que el diálogo no es realmente aporético, a pesar de que Sócrates parece considerarlo así. Como hemos adelantado, Sócrates, un hombre mayor, se cuenta a sí mismo como amigo de los jóvenes. ¿En qué sentido podría ser esto?

No en un sentido utilitario ni erótico en su acepción vulgar, sino en la búsqueda del bien, que en este caso se concreta como búsqueda del conocimiento de sí mismos, de lo que ellos tienen de propio y de bueno. En el contexto del diálogo lo bueno es que Sócrates los ha llevado a experimentar lo que es la amistad en la búsqueda en común, los ha refutado parcialmente al afirmar que existe un fin en sí mismo y que no toda relación humana se reduce al deseo de placer erótico (Hipótales) o a la utilidad técnica (los padres de Lisis). El fracaso del argumento se debe a que los jóvenes no son capaces de descubrir que las categorías absolutas no corresponden a la realidad cambiante ni pueden admitir la identidad de lo propio y el bien en todas las cosas. Y Sócrates no puede forzarlos a hacerlo.

Un signo de que él no se conforma con el resultado negativo se pone de manifiesto cuando confiesa que estuvo a punto de buscar el apoyo de 'algún otro de los mayores' (223a) probablemente para intentar persuadir a los otros jovencitos. No pudo conseguirlo, porque el diálogo es interrumpido bruscamente por los pedagogos quienes consiguen disolver la reunión.

\section{5. ¿QUÉ NOS DICEN EL LÓGOS Y LA ACCIÓN DRAMÁTICA?}

El bien es lo propio de todo, según Sócrates y lo que todos buscan. No existen en realidad ni los absolutamente buenos ni los completamente malos en sentido absoluto. El diálogo parece terminar en aporía porque parte de categorías absolutas atemporales en las que no hay proceso, ni cambio, ni vida.

\footnotetext{
${ }^{18}$ Ferrari (1998, p. 22).

19 También para Kahn (1996) entre 216c y 221d se encuentra la implícita conclusión positiva del diálogo. Esos resultados se mantienen. Rowe (2000, p. 207) sostiene que Sócrates no está simulando no haber alcanzado una conclusión, sino que su tesis es compleja y requiere un desarrollo ulterior que él encuentra en la enseñanza de Diotima en el Banquete donde se establece que uno ama aquello de lo que carece y que el bien es el objeto universal de amor o deseo (205e-206a).

${ }^{20}$ Bossi (2000).
} 
En todos y en todo anida el bien, que es lo más propio, y lo que llama al bien como objeto de deseo, de amor y de amistad. Lo que se busca en todos los casos es el bien que ya poseemos en parte pero que no poseemos completamente.

En consonancia con esta visión, Aristóteles sostendrá que los buenos no sólo 'necesitan' amigos sino que la amistad entre iguales por amor del bien que ellos disfrutan es la mejor y la más auténtica, si la comparamos con la amistad utilitaria propia de la vejez o con la amistad por el placer erótico, propia de los jóvenes. Los buenos necesitan amigos como objeto de sus buenas acciones; para perseverar en el bien, ya que no permiten a sus amigos cometer errores y para conocerse a sí mismos: los amigos son un alter ego. La consciencia de uno mismo como 'bueno' hace la existencia deseable y placentera, pero la contemplación directa de uno mismo es imposible, sólo es realizable a través de los amigos. ${ }^{21}$

Ser amigo de uno mismo es ser amigo de lo más propio de cada uno, es decir, del bien que somos, siquiera parcialmente. Esto puede confirmarse en el papel que desempeña la noción de 'propio' con relación a lo justo tal como se desarrolla en la República. ${ }^{22}$ Ser amigo de otro es buscar en el amigo y con el amigo el desarrollo de lo más propio de ambos, que es, otra vez el bien. Pero ¿de qué bien está hablando Sócrates?

En este diálogo (y también en el Gorgias y en el Protágoras) Sócrates sostiene que lo bello y lo bueno son lo mismo. Tò kalón puede traducirse como 'lo bello' pero es también 'lo noble' y 'lo admirable' por lo que cabría interpretar el bien en sentido ético. Pero también es bello el diálogo filosófico. Y en nuestro caso, ha sido fecundo. ${ }^{23}$ Veamos cómo han cambiado nuestros cuatro personajes principales.

En primer lugar podemos preguntarnos: ¿Qué ha sucedido en la acción dramática para que Sócrates, el amante de amigos que dice que no sabe cómo hacerse con ellos, acabe por contarse a sí mismo como amigo de estos jovencitos?

${ }^{21}$ Ética Nicomaquea, 1169b3- 1170b19; 1159b2-11; Magna Moralia, 1213a10-26. Sin embargo, para Aristóteles la amistad no es un género común y uno sino que su unidad es solamente de referencia prós hen hacia esta amistad excelente entre iguales en la virtud.

${ }^{22}$ En la República, ser amigo de uno mismo es ser 'uno' consigo mismo, i.e. dar a cada parte del alma lo suyo (su objeto de deseo) en la medida adecuada para que reine la moderación en todas las partes y estén de acuerdo en que debe gobernar la razón (porque tiene la mejor visión del conjunto) y así resulte la justicia en el todo. En forma análoga, ser amigo de la ciudad significa ser uno con ella, lo cual supone igualmente la moderación (entendida como el conocimiento de los propios límites) para acordar quien debe gobernar de modo que reine la justicia.

${ }^{23}$ Estoy de acuerdo con Bordt (2000) en que el bien es lo propio de los amigos y es también su fin, lo amado por sí mismo, no utilitariamente sino el objeto último de su deseo, por lo cual dos personas pueden ser llamados amigos, en sentido estricto. Ferrari (1998, p. 25-27) interpreta que el bien propio que deseamos y que nos ha sido sustraído, del que estamos privados, es el mundo de las ideas que el alma pudo atisbar antes de nacer: 'Es propio del alma sólo aquello que es accesible a su facultad cognitiva suprema (nô̂s) en virtud de una parentela ontológica perdida' (p. 26). El autor no considera que ésta sea la única posible interpretación, naturalmente, pero encuentra apoyo de su enfoque en pasajes de Fedón (79d3; 75e1-7) y de República (611e2-3).

Classica, v. 31, n. 1, p. 199-213, 2018 
Sócrates pone atención a los intereses y preocupaciones de estos jóvenes, ${ }^{24}$ sea el deseo de ganar el favor de Lisis por parte de Hipótales o el deseo de humillar a su rival por parte de Lisis. Con esas excusas comienza Sócrates a dialogar con ellos. Progresa el diálogo sinuosamente. Lisis se muestra una presa difícil de subyugar con artes torpes. Hipótales toma nota de que la adulación no es el camino. Y el discutidor Menéxenos, al optar por un movimiento en falso, se queda sin definición de 'amigo'. No hay victoria para él.

A mi modo de ver, Sócrates lo ha refutado con sus propias armas con el objetivo de volverlo más suave y tolerable para sus amigos. ${ }^{25}$ Indirectamente Sócrates consigue cambiar la perspectiva y quizás también el modo en que se relacionen estos tres personajes entre sí, por medio de su modo peculiar de ponerlos a prueba.

Si no percibiéramos la ironía de Platón, hasta podríamos pensar que Sócrates mismo cambia de situación porque gana tres nuevos amigos, en la medida en que los intenta llevar hacia lo mejor de sí mismos, i.e. hacia la conciencia de los propios límites, ${ }^{26}$ sean emocionales, como es el caso del impulsivo Hipótales o intelectuales, como es el caso del discutidor Menéxenos.

\section{A MODO DE CONCLUSIÓN: SI EROS DEL BIEN, ENTONCES PHILÍA}

1. Frente a la mostración exclusiva de éxito, el reto platónico sobre la amistad acaba en fracaso. Es un fracaso aparente porque constituye el mejor regalo que nos puede hacer Sócrates: escamotearnos la solución para retarnos a buscarla;

2. Frente a la inmediatez, la amistad se genera progresivamente entre varios con un mismo fin: la búsqueda de lo propio en lo otro, i.e. el bien.

3. Frente a la idiotización auto-referencial y superficial, el diálogo platónico se centra en una cuestión a definir. La solución no se facilita. Se mantiene en un plano semioculto que se resiste a ser revelado explícitamente. Es accesible

\footnotetext{
${ }^{24}$ También en el Fedro Sócrates se muestra como 'amigo' de su interlocutor, en cuanto soporta con paciencia las veleidades de Fedro en la primera parte, hasta el punto en que debe cortar de cuajo sus juegos de seducción y rivalidad, porque sus pretensiones atentan contra la verdad: no se debe complacer al que no ama; el único que merece el amor de los jóvenes es el que los ama con pasión filosófica. Al regresar de su intento fallido de cruzar el río, y habiendo recuperado su atención, Sócrates consigue elevar la autoestima de Fedro a través de la belleza de un canto nuevo que le revela su naturaleza divina. Finalmente, acabado el mito, el amigo Sócrates le muestra sus propias cartas y le enseña a amar a otro del mismo modo.

${ }^{25}$ Si el discípulo quedara estéril, 'será menos pesado y más tratable para sus amigos', pues tendrá la sensatez de no creer que sabe lo que ignora. Esto y nada más es lo único que el arte mayéutico de Sócrates puede lograr (Teeteto, 210c1-5).

${ }^{26}$ No es otra la lección del Cármides. Si la moderación, en su acepción popular, puede fijar la medida adecuada de cara a los placeres, es porque en sentido filosófico profundo, consiste en tomar consciencia de los propios límites.
} 
pero hay que centrarse en la presa, rastrearla y retroceder en busca de pistas e indicios. Al hacerlo los cazadores manifiestan destrezas y fallos.

4. Frente a la manipulación, el amigo no es un medio para que uno sea admirado, aplaudido o adulado, ante cualquier nimiedad. El objeto del deseo no es un medio para otra cosa, sino un fin en sí mismo. Queremos saber lo que es 'ser amigo' para saber lo que es desear o amar, para saber lo que deseamos y en qué consiste nuestro bien propio.

5. Frente al exhibicionismo, la amistad requiere intimidad y complicidad. El amigo no expone los fallos del amigo en público, sino que, conociendo sus preocupaciones, intenta cuidar del él para que alcance lo que tiene de más propio, i.e. su bien. Sin consciencia de ignorancia y límites no hay deseo. Sin deseo corremos el riesgo de morir. Morir de éxito y adulación.

Para finalizar, una pregunta. Si el alma no sale en pantalla y los procesos emocionales profundos no encuentran el ámbito adecuado en la visibilidad expuesta de los amigos innumerables y de los seguidores superficiales, ¿no corremos el riesgo de generar una doble vida: la del éxito expuesto, por una parte, y la de las emociones reales, acaso ligadas a lo que erróneamente podamos considerar un fracaso, aunque en verdad no lo sea? ¿Cómo puede un amigo virtual conocer esa otra vida que necesariamente debe permanecer oculta? Y si no la conoce, ¿cómo puede contribuir a su cuidado para provocar el crecimiento del amigo? ¿Un mundo feliz de éxitos, celebraciones y diversión en constante exposición ininterrumpida, no acaba por dejarnos hastiados, por imposible y ficticia?

\section{REFERENCIAS}

ADAMS, D. The Lysis Puzzles. History of Philosophy Quarterly, v. 2, p. 3-17, 1992.

ANNAS, J. Plato and Aristotle on Friendship and Altruism. Mind, New Series, v. 86, n. 344, p. 532-554, 1977.

BOLOTIN, D. Plato's Dialogue on Friendship. Ithaca; London: Cornell University Press, 1979.

BORDT, M. The Unity of Plato's Lysis. In: ROBINSON, T. M.; BRISSON, L. (Ed.). Plato, Euthydemus, Lysis, Charmides. Selected Proceedings of the V Symposium Platonicum. Sankt Augustin; Academia Verlag, 2000. p. 157-171.

BOSSI, B. Is the Lysis Really Aporetic?. In: ROBINSON, T. M.; BRISSON, L. (Ed.). Plato, Euthydemus, Lysis, Charmides. Selected Proceedings of the V Symposium Platonicum. Sankt Augustin; Academia Verlag, 2000. p. 173-179.

FERRARI, F. L'oikeion dell'anima e la conoscienza filosofica: il motivo gnoseologico nel Liside, Acta Universitatis Carolinae-Philologica 3 Graecolatina Pragensia XVI-XVII, 1998. p. 21-27.

GONZÁLEZ, F. How to read a Platonic prologue: Lysis 203 a-207d. In: MICHELINI, A. (Ed.). Plato as Author: The Rhetoric of Philosophy. Leiden; Boston: Brill, 2003. p. 15-44. 
IRWIN, T. Plato's Moral Theory. Oxford: Clarendon Press, 1977.

KAHN, C. Plato and the Socratic Dialogue. The Philosophical Use of a literary Form. Cambridge: Cambridge University Press, 1996.

NARCY, M. Le Socrate du Lysis est-il un Sophiste?. In: ROBINSON, T. M.; BRISSON, L. (Ed.). Plato, Eutbydemus, Lysis, Charmides. Selected Proceedings of the V Symposium Platonicum. Sankt Augustin: Academia Verlag, 2000. p. 180-193.

NICHOLS, M. Friendship and Community in Plato's Lysis. The Review of Politics, v. 68, p. 1-19, 2006.

PRICE, A. Love and Friendship in Plato and Aristotle. Oxford: Oxford University Press, 1989.

RESHOTKO, N. Plato's Lysis: A Socratic Treatise on Desire and Attraction. Apeiron, v. 30, p. 1-18, 1997.

ROWE, C. The Lysis and the Symposium: aporia and euporia?.In: ROBINSON, T. M.; BRISSON, L. (Ed.). Plato, Eutbydemus, Lysis, Charmides. Selected Proceedings of the V Symposium Platonicum. Sankt Augustin, Academia Verlag, 2000. p. 204-216.

VLASTOS, G. The Individual as Object of Love in Plato. Platonic Studies, p. 3-34, 1981. 